Some stories, however, were even too much for Burton, who quotes, with his tongue in his cheek, the story of the Roman Prince and the Jewish Rabbi who was asked why the Jew's God was compared to a lion. The reply came that it was no ordinary lion but one in the Wood Ela which, when he asked to see it, the Rabbi prayed to God he might, "and forthwith the lion set forward. But when he was 400 miles from Rome he so roared that all the great-bellied women in Rome made abortions, the City walls fell down, and he came a hundred miles nearer, and roared a second time, their teeth fell out of their heads, the Emperor himself fell down dead, and so the lion went back.'

In contrast to these myths we are provided with a deal of factual information here and there. For instance we know that Philip, the French king, who married the King of Denmark's daughter, sent her back to her father after the first night because her breath stunk. The strict observance of ritual with its severe discipline led to the martyrdom in 1270 of a Jew who "fell into a privy upon a Saturday and without help could not possibly get out; he called to his fellows for succour, but they denied it, because it was their Sabbath; the bishop hearing of it the next day forbade him to be pulled out because it was our Sunday. In the meantime the wretch died before Monday.'

So we have wandered at random through the pages of this remarkable book which, in some ways, might be regarded as one of the earliest books written in English on psychiatry. Jordan Smith writes, ' his great book is the enduring expression of a widely read scholar, of a clever craftsman, who had the genius to knit together threads from as thousand looms and thus to make a fine, stout $\stackrel{\mathbb{Q}}{\complement}$ pattern all his own.'

We have heard how Burton used to go down to $\overrightarrow{\overrightarrow{\mathrm{S}}}$ the Bridge-foot at Oxford and listen to the bargees and how for three years he was a Clerk to $\bar{\sigma}$ the Market; he was a keen student of human $\frac{\bar{c}}{\bar{m}}$ nature.

His concept of melancholy embraced a much \% wider field of mental disorders than we would accept today. He describes the hysteric and illustrates many other types in whom the prominent symptoms are hallucinations, delusions, perversions and compulsions. Nevertheless the apprehension and fear experienced by the melan- 3. cholic is very real and far from 'imaginary,' the sense of unworthiness and the narrow margin $\mathrm{N}^{-}$ between the pathological and the normal is fully 0 realized. 'Some are so gently melancholy, that in 0 all their carriage, and to the outward apprehension

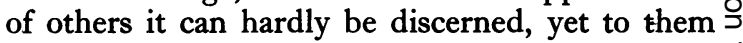
an intolerable burden, and not to be endured.' $\rightarrow$ Many of his ideas on therapy are fundamentally sound and he is fully alive to the conflicts and repressions of the mind. The need for social $\vec{\varphi}$ reform as outlined in the Utopia he describes, is indeed applicable to our present-day protoㅇㅇㅇ lems.

\section{BIBLIOGRAPHY}

BLACKWOOD, Vol. $90,323,186 \mathrm{r}$.

BURTON, Anatomy of Melancholy, edited by A. R. Shilleto, Georgə Bell \& Sons, 1896.

EVANS, Bergen Psychiatry of Robert Burton, Columbia Univ. Press, 1944.

JORDAN-SMITH, PAUL, Bibliographia Burtoniana, Stanford Univ. Press, 1931.

\title{
MODERN THERAPY OF THYROTOXICOSIS
}

By J. F. Goodwin, M.D., M.R.C.P.

From the Department of Pharmacology and Therapeutics, University of Sheffield, and the Royal Infirmary, Sheffield.

In 1943, Astwood and his associates, on the basis of animal experiments, concluded that thiourea and its derivatives inhibited the synthesis of thyroxin and that the resultant deficiency of thyroxin resulted in an increased output of pituitary thyrotropin, which produced thyroid hyperplasia. This thyroid hyperplasia was not influenced by large amounts of iodine but was abolished by the administration of thyroid powderco and by hypophysectomy. There was also almost complete disappearance of iodine from the thyroid? gland after five days on thiouracil, suggesting $\frac{T}{T}$ that thiouracil interfered with enzyme systems necessary for the normal conversion of di-iodo- $\bigcirc$ tyrosine to thyroxin.

Later in 1943, Astwood investigated other re- 
lated compounds, 2-thiouracil, 2-thiobarbituric acid and di-ethyl thiourea, and conducted clinical trials with thiourea and thiouracil. He concluded that both were effective anti-thyroid drugs producing a remission in the thyrotoxic process in one to two weeks and a recurrence when the drug was discontinued. These results were later confirmed in this country by Himsworth.

Following this work thiouracil was hailed with more enthusiasm than discrimination as the final answer to the treatment of thyrotoxicosis, and a spate of clinical reports on the drug appeared in the literature. The first flush of success was succeeded by the inevitable reaction and anticlimax as the complications of therapy became known.

Reference is omitted to those thiouracil compounds such as thiobarbital and thiourea, which have been tried and largely discarded. The three thiouracil compounds now in clinical use for the treatment of thyrotoxicosis are :-

Thiouracil.

4-Methyl Thiouracil.

6-N Propyl Thiouracil.

These compounds all act by preventing the synthesis of thyroxin by interfering with enzyme systems necessary for the conversion of di-iodotyrosin to thyroxin. They compete with the precursors of thyroxin for the availabble body iodine. The action of thouracils can therefore be inhibited by the administration of iodine-containing drugs. The fall in thyroxin level produced by thiouracil reflexly stimulates the anterior pituitary gland to secrete more thyrotropic hormone, which produces enlargement of the thyroid gland in an attempt to raise the thyroxin level. Thiouracil is very rapidly absorbed from the stomach and duodenum and reaches a high concentration in the pituitary, thyroid and adrenal glands and also in the bone marrow. The white blood cells take up relatively greater amounts of the drug than the red blood cells, a fact which is important in considering the possible complications of the drug. One third of the drug is excreted in the urine, the remainder broken down in the body, probably in the liver. Within one to two days of commencing administration, the organism is unable to synthesize thyroid hormone and the quantity of circulating thyroxin falls. This calls forth the pituitary response which stimulates thyroid gland hyperplasia. This hyperplasia is less marked in human beings than in animals.

\section{Thiouracil}

Originally the dose given of this compound was I gm. daily and doses of up to $1.4 \mathrm{gms}$. daily have been used. These figures are now known to be too high, and were probably responsible for the early and somewhat exaggerated reports of complications. The maximum daily dose now permissible is $.8 \mathrm{gm}$., and patients are usually treated with $.6 \mathrm{gm}$. daily until control is obtained in one to two weeks. The dose is then reduced to .2 to $.4 \mathrm{gm}$. daily and the average maintenance dose is $.15 \mathrm{gm}$. daily. Subjective improvement generally occurs at the end of seven or eight days and is followed a day or two later by a fall in pulse rate, diminution in sweating and tremor, and a gain in body weight which is not usually evident until I4 to 2 I days after starting treatment.

Methyl thiouracil, however, has to a large extent superseded thiouracil. Investigation has shown that certain derivatives of thiouracil are less toxic than thiouracil itself ; 4-methyl thiouracil is more easily and safely manufactured, effects control of the disease more quickly and requires a smaller maintenance dose than thiouracil. In addition there is a diminished incidence of thyroid hyperplasia and toxic reactions. The initial dose of methyl thiouracil is also $.6 \mathrm{gm}$. daily and objective control is usually achieved in five to seven days, when the dose is reduced to .3 or $.4 \mathrm{gm}$. daily. The average maintenance dose is $.05 \mathrm{gm}$. daily after four to six weeks treatment on .2 gm. daily.

Astwood and Van der Laan investigated two other derivatives of thiouracil-6-ethyl thiouracil and 6-N-propyl thiouracil. The former showed a high order of activity but was abandoned in favour of propyl thiouracil owing to difficulty of synthesis of the former and apparent superiority of the latter. Subsequent work has shown that in humans propyl thiouracil is four times more potent than methyl thiouracil in equivalent doses. The dosage given is, therefore, considerably smaller and .I $5 \mathrm{gm}$. is the usual daily initial dose. A satisfactory response is usually obtained in five to seven days, when the dose is reduced to $.075 \mathrm{gm}$. daily. The average maintenance dose is $.05 \mathrm{gm}$. daily, although patients have been maintained on a dosage as small as $0.0125 \mathrm{gm}$. daily. Propyl thiouracil offers no outstanding advantage over methyl thiouracil and is considerably more difficult and expensive to manufacture. I have found (Wilson and Goodwin, 1947) that the incidence of toxic reactions and thyroid hyperplasia is not appreciably less with propyl than with methyl thiouracil although Lahey, McCullagh and Astwood consider propyl thiouracil to be less toxic than methyl thiouracil. Livingstone and Livingstone have recently reported a case of total agranulocytosis and jaundice in a patient treated with propyl thiouracil.

\section{Treatment with Methyl Thiouracil}

I. Changes in the thyroid gland

Definite hyperplasia occurs in about 40 per 
cent. of cases, but it is usually not marked. Gross enlargement is occasionally seen with the smaller dosage now used, but is unusual. Decrease in size of the goitre is rare.

\section{Exophthalmos}

Some reduction in exophthalmos may be expected to occur in cases of mild or moderate degree and recent onset. No change occurs in severe cases with a long history of hyperthyroidism. Increase in exophthalmos is uncommon.

\section{B.M.R. and Blood Cholesterol}

The B.M.R. usually falls to normal levels two to three weeks after starting therapy, thus showing a lag behind the control of objective signs. The blood cholesterol level parallels the B.M.R. and the former rises as the latter falls. Neither of these estimations, especially the cholesterol, is as reliable as the objective clinical signs of improvement. Typical cases show an initial blood cholesterol in the region of $130 \mathrm{mgm}$. per cent., which rises to 180 to $200 \mathrm{mgm}$. per cent. after two to three weeks' treatment. The B.M.R. commonly falls from the region of +40 to +10 . It is, of course, the change in values that is of importance, rather than single estimations before or after treatment. It should be remembered that the B.M.R. in normal persons may vary between $-\mathrm{I} 5$ and $+\mathrm{I} 5$.

\section{Auricular fibrillation}

There is a reasonable prospect of sinus rhythm being restored, particularly in patients without additional coronary artery disease, and with fibrillation of recent onset. In cases where the preliminary electrocardiograph shows evidence of coronary insufficiency, the chances of restoring sinus rhythm are small, so that such tracings have a prognostic significance. The latent period before sinus rhythm returns, varies from 12 days to six months. Of 20 cases with fibrillation which have been treated at the Endocrine clinic with thiouracils, six were restored to sinus rhythm (see table). The use of quinidine to restore normal rhythm is worth consideration in patients in whom the arrhythmia persists after six months' treatment with methyl thiouracil, although embolization from thyrotoxic fibrillation is not common.

\section{Thyrotoxic heart failure}

The response to methyl thiouracil is usually excellent, and except in severe cases, all that is required apart from rest in bed. Severe cases require in addition the usual treatment for congestive heart failure. Mercurial diuretics are indicated when oedema is marked. In cases so urgent that the latent period before methyl thiouracil exerts its effect may prove fatal, intravenous digoxin is of
Thyrotoxic Auricular Fibrillation and Thiouracil Compounds

\begin{tabular}{|c|c|c|c|}
\hline & & $\begin{array}{l}\text { No. of cases } \\
\text { with A.F. }\end{array}$ & $\begin{array}{l}\text { No. of cases which } \\
\text { reverted to sinus } \\
\text { rhythm after to to } 24 \\
\text { month's trt. }\end{array}$ \\
\hline Thiouracil & . & 5 & I $(20 \%)$ \\
\hline $\begin{array}{l}\text { Methyl } \\
\text { Thiouracil }\end{array}$ & $\cdots$ & 9 & $3(33.3 \%)$ \\
\hline $\begin{array}{l}\text { Propyl } \\
\text { Thiouracil }\end{array}$ & $\cdots$ & 6 & $2(33.3 \%)$ \\
\hline Total & . & 20 & $6(3 c \%)$ \\
\hline
\end{tabular}

value. It should be remembered, however, that the response to digitalis in this type of heart failure is not so satisfactory as that in heart failure due to rheumatic or hypertensive heart disease.

\section{The thyroid crisis}

This catastrophe is happily now becoming much less frequent than formerly. When it occurs it usually follows thyroidectomy but occasionally cases of primary fulminating myasthenic thyrotoxicosis are seen in young women. Treatment with thiouracil by mouth is obviously useless and little is known of the results of intravenous injection. The treatment of this condition at present remains the administration of Lugol's iodine per rectum, or sodium iodide intravenously, with liberal oxygen, if necessary in a tent, and sedation.

\section{Primary thyrotoxicosis}

Methyl thiouracil produces excellent results in this condition, but not infrequently, cases of what may be termed 'pituitary thyrotoxicosis' fail to respond satisfactorily. The patient is usually a young girl, with a very large vascular goitre, gross tachycardia and peripheral vasodilatation, marked exophthalmos and moist warm skin, but not a great deal of wasting or nervousness. This type of case responds badly to treatment. The essential lession lies in the pituitary gland and thyroid signs are merely the expression of pituitary stimulation. Whatever form of therapy, surgical or medical, is directed at the thyroid gland, it can only be partly. successful, since it does not strike at the root of the disease. Thiouracil is no exception to this rule. There is some justification for combining deep X-ray therapy to the pituitary gland with the administration of thiouracil in these cases.

\section{Toxic adenoma}

It has often been stated that the toxic adenoma does not respond well to thiouracil. The experience of the writer is that not only do such cases react well, but often do better than cases of primary thyrotoxicosis. Thiouracil is indicated in 
this type of case, except in certain circumstances which will be mentioned later.

\section{Pregnancy and lactation}

Early reports were unfavourable on the use of methyl thiouracil in pregnancy, since, on the basis of animal work it was thought that the drug could penetrate the placental barrier and produce cretinism in the foetus together with an enlarged thyroid gland. The possibility that excess of maternal thyrotropic hormone might stimulate the foetal thyroid, was also raised.

Scandinavian workers (Kjerulf-Jensen and Meulengracht) claim that, using rats, no thiouracil penetrates the placental barrier unless sufficient of the drug is given to render the mother myxoedematous. They have shown, however, that the drug is excreted in fairly high concentration in the breast milk. It has been suggested that in pregnant women treated with thiouracil, the drug should be discontinued one to two weeks before term, and iodine therapy substituted in order to avert foetal goitre and hypothyroidism. This is not rational therapy since the control of hyperthyroidism will be lost at the vital time when delivery occurs. Also the response to thiouracil in the puerperium will be vitiated by the iodine administration.

In my view the risk of changes in the human foetus is very small, unless sufficient amounts of thiouracil are given to the mother to render her myxoedematous. If small maintenance doses are used, methyl thiouracil will be instrumental in producing an uneventful pregnancy and a healthy child for many patients who might otherwise come to therapeutic termination of pregnancy or miscarriage. During the puerperium, if the child is breast fed the dose of methyl thiouracil should be kept to the minimum, about .025 to $.05 \mathrm{gm}$. daily, and the infant should be carefully watched for signs of hypothyroidism. Reduction in dose is often possible at this time since thyrotoxicosis tends to remit to some extent after delivery. During the past year I have treated four pregnant patients along these lines with complete success so far.

Provided that a pregnant woman with thyrotoxicosis responds satisfactorily to methyl thiouracil, there should be no need to advise termination of pregnancy unless other complicating factors are present.

\section{Thiouracil and Previous Iodine Treatment}

It is now an established fact that previous iodine treatment renders patients refractory to thiouracil, probably by building up a store of iodine in the thyroid gland from which thyroxin can be synthesized without hindrance. The response to methyl thiouracil is delayed and ineffective until the iodine has been eliminated. Previous iodine treatment, therefore, prejudices the chances of a patient who has been selected for thiouracil treatment.

\section{Complications}

Modified From McCullagh, I946

These may be grouped under three headings, but I shall deal in detail with only the important ones :-

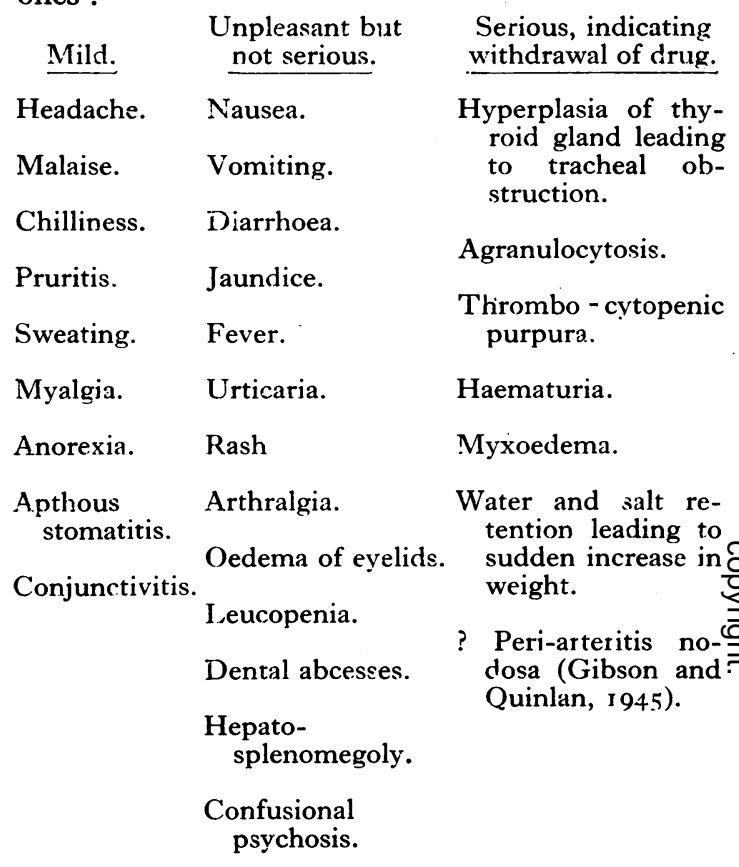

\section{Agranulocytosis}

It will be remembered that a tendency to leucopenia is a feature of thyrotoxicosis. Much wider variations probably occur in the white cell count in this disease than in normal persons. There is no doubt whatever that thiouracil exerts a direct depressant effect on the bone marrow. Thiouracil is rapidly taken up by the white blood cells in the marrow in high concentration and agranulocytosis may occur as a sensitivity effect early in treatment or as a result of direct poisoning of the bone marrow by high dosage and protracted therapy. This latter tendency has been made the basis of the treatment of leukaemia with thiouracil in America (Limarzi et al., 1946). The agranulocytosis may be of two types; the first and, fortunately, the commoner type in which there is a deficiency in maturation of white cells at the pre-myelocyte or myelocyte level, and the second and much graver type in which granulopoiesis is inhibited at the myeloblast level. These two types can readily be differentiated by examination of a marrow biopsy, an investigation always to 
be performed if agranulocytosis is feared. Figures vary for the incidence of agranulocytosis but McCullagh quotes 2I deaths from this complication out of 5,700 cases treated, a mortality rate of one-third of I per cent. Leucopenia occurred in 3 per cent. of cases.

In the last year out of I I I patients treated by me with thiouracils there have been seven cases of leucopenia but no cases of agranulocytosis. There were no deaths and it was possible to restart therapy in all but three patients. No rigid critical level for leucopenia is taken, but total counts of 3,000 or less, with less than 1,500 polymorphs are held to be an indication for withdrawal of therapy and close observation, with sternal marrow biopsy if a second blood count within 12 hours does not show a rise in polymorphonuclear cells. Total polymorphonuclear counts of 500 or less indicate agranulocytosis.

\section{Prevention and Treatment}

All patients treated with methyl thiouracil should be in hospital for the first two weeks. White blood cell counts are performed three times weekly while the patient is in hospital, once fortnightly for the first month following discharge and then once every two months. All patients should be instructed to stop taking the tablets and report at once if they develop a sore throat or rash. I give patients who are leaving the district for a short time a note stating the dosage of methyl thiouracil, which they are instructed to take to the nearest doctor if they develop any of the symptoms mentioned. It is questionable whether regular blood counts after discharge from the ward are of value, since agranulocytosis may develop with devastating rapidity and a patient with a normal count one day may have no polymorphonuclear cells the next. On the other hand, normal white cell counts tend to inculcate a false sense of security into the mind of the clinician.

The treatment of agranulocytosis consists of immediate withdrawal of the drug, and penicillin therapy in full dosage to control the resultant infection until the bone marrow has a chance to recover, as it usually does. Blood transfusion may be of value also. Of so-called stimulators of leucopoiesis, the most effective is probably pyridoxin by intramuscular injection in doses of 100 to $200 \mathrm{mgm}$. daily. The best guide to prognosis is examination of a marrow biopsy.

\section{Jaundice}

It is well known that a fine hepatic cirrhosis occurs in thyrotoxicosis, though only very seldom does liver damage give rise to clinical signs, and jaundice, though unusual, sometimes occurs (Moschowitz, 1946).
Methyl thiouracil is broken down in the tissues, probably in the liver, and might be considered as a potential liver poison. Five cases, one fatal, of jaundice following thiouracil therapy, have been reported in the literature. The fatal case died from associated agranulocytosis and there was little, if any, evidence of liver damage at autopsy. The other four cases showed transient jaundice which disappeared after discontinuing thiouracil(Kahn and Stock, Gr rgil and Lesses, Sloan and Shorr, 1944-5).

Following the death of a patient suffering from thyrotoxicosis (and on methyl thiouracil therapy) from choleaemia due to multilobular hepatic cirrhosis, I became interested in the possibility of methyl thiouracil as a liver poison. In the last six months 72 cases attending the Endocrine Clinic have been subjected to liver function tests at twoto three-monthly intervals. The tests in use are serum bilirubin; takata ara, thymol turbidity, alkaline phosphatase and the total and differential plasma proteins. One patient developed icterus, which was subsequently shown to be due to biliary congestion and low-grade hepatosis due to thyrotoxicosis, and which disappeared on resuming methyl thiouracil therapy. In only one other case was hepatomegaly noted, in a male patient whos developed a maturation type of leucopenia with transient enlargement of liver and spleen. Live function tests were normal.

The investigation continues and full results wili be published later, but my impression is that, while it may be argued that the liver function tests are not sensitive enough to reveal minor degrees of liver damage, thiouracil seems unlikely to cause serious liver damage and that a mild or moderate degree of liver damage is no contra-indication to its use.

\section{Thyroid Gland Hyperplasia}

Hyperplasia sufficient to cause tracheal compression is distinctly rare, but occasionally occurs in the pituitary type of case. Slight degrees of hyperplasia are no indication for discontinuing therapy, unless the enlargement is substernal and stridor present. The use of small doses of thyroid extract along with thiouracil to inhibit the pituitary thyrotropin is rational in theory but disappointing in practice.

\section{Sudden Increase in Weight}

This sometimes occurs, and is possibly due to loss of the diuretic action of thyroxin leading to water and salt retention. There may also be a stimulation of the posterior pituitary anti-diuretic factor. I have seen this complication occur in the pituitary type of case. Water and salt balance can usually be adjusted by reducing the dose of methyl thiouracil. 


\section{Contra-indications to Thiouracil}

I. Very large goitres with tracheal compression.

2. Retrosternal goitres of more than slight extent and those showing tracheal compression. Very small retrosternal goitres without narrowing of the trachea need not prove a bar to therapy, provided that close watch is kept on the patient for signs of enlargement. The retrosternal area should always be X-rayed for evidence of tracheal compression before thiouracil is given.

3. A previous history of leucopenia from thiouracil or sulphonamide, a drug rash, or other toxic phenomena other than mild reactions. A white blood cell count should always be performed before starting therapy.

4. Inability to attend for regular supervision.

5. Uncooperative patients who are unlikely to follow their instructions.

6. Malignant goitre (very rarely toxic).

\section{Absolute Indications for Discontinuing the Drug}

I. Severe leucopenia or agranulocytosis.

2. Gross enlargement of the thyroid gland with or without tracheal compression.

3. Failure to respond to the drug.

4. Hypothyroidism.

Relative Indications for Discontinuing the Drug Temporarily or Reducing the dose

I. Sudden water retention with rapid increase in weight and possible oedema.

2. Rash, jaundice, slight leucopenia and other mild or moderate reactions.

\section{Thiouracil and Surgery}

Surgeons have long been aware of the poor results of operation on the young girl with marked hyperthyroidism and a large vascular goitre, although iodine preparation and improved operative technique has much improved prognosis. There has, however, recently been a marked tendency to advise operation in all cases of nodular goitre whether toxic or not. Keynes and others maintain that all nodular goitres (pseudoadenomata) will eventually become toxic and give rise to auricular fibrillation. Papp states that 80 per cent. of cases of thyrotoxicosis fibrillate by the age of 60 . This, alone, is considered by some to be an adequate indication for surgery. In addition, there is no doubt that the non-toxic nodular goitre is potentially malignant, although malignant adenomata are only rarely toxic. Again, there is the problem of pressure symptoms, which are nften present in nodular goitres, or may develop suddenly if haemorrhage occurs into a cyst. The choice of medical or surgical treatment in the non-toxic adenoma depends on two factors- evidence of malignancy and the presence of pressure symptoms. If either of these are evident, operation is unquestionably indicated without delay. If neither of these complications exists the problem is more difficult. Toxicity need not be feared, for methyl thiouracil will satisfactorily control this, but the development of malignancy cannot be prevented, nor can a sudden haemorrhage into the cystic space causing sudden obstruction, be guarded against. If the goitre is large, or there is more than one adenoma, then operation is to be desired. If there is but one small adenoma then the case may safely be left, but should be kept under observation. Enlargement, hardening, or pain in the goitre are signs suggestive of malignancy and operation should be advised. No case should be left until regional lymph nodes have become involved. In America, according to Papp, 7.2 per cent. of a series of 523 non-toxic goitres of all kinds and 24 per cent. of a series of single non-toxic adenomata, were malignant. So high an incidence of malignancy is certainly not reported in this country and it is, perhaps, unwise to base treatment in this country on figures obtained from another. The patient with auricular fibrillation and a toxic adenoma, unless the goitre is causing tracheal compression, should be treated by methyl thiouracil and, if necessary, by quinidine to restore sinus rhythm. Himsworth, Trotter and Morgans have recently analysed a series of cases treated by thiouracil and another series treated by operation. They find that the response to thiouracil is not so rapid as that to operation, but the long-term results are probably very similar. With an expert surgical team, the mortality rate of operation is slightly less than I per cent., while the mortality rate from methyl thiouracil is in the region of .3 per cent. to .5 per cent. With surgeons of less experience the mortality rate rises considerably. There is thus adequate reason for considering methyl thiouracil, rather than surgery, to be the treatment of choice. A further reason for regarding methyl thiouracil as a more rational treatment than operation is the fact, noted by the older clinicians, that thyrotoxicosis tends to natural remissions and to burn itself out. Albutt; in I897, stated that about $5^{\circ}$ per cent. of cases recovered completely without, as we now know, adequate treatment. Therefore, the object of treatment should be to induce a permanent remission, and it is more reasonable to do this by medical than by surgical means, particularly as no claims of permanent cure can be made for any form of treatment unless the cure rate is definitely above $5^{\circ}$ per cent.

\section{Surgery Combined with Thiouracil}

There is no doubt that thiouracil given pre- 
operatively can convert the patient into a better operative risk than treatment with iodine alone. Early trials revealed that thiouracil produced a very vascular gland, which increased the difficulties and dangers of the operation. This disadvantage has been overcome by withdrawing thiouracil two to three weeks before operation and substituting iodine, which fibroses the gland (Bartels). This is now the practice at the Lahey clinic where, in a series of 23,000 patients subjected to operation with and without pre-operative thiouracil, the mortality was .75 per cent. The thiouracil compounds used pre-operatively have abolished the necessity for the two or three stage thyroidectomy. Lahey himself considers propyl thiouracil to be less toxic than methyl thiouracil and used this derivative as a routine.

The combination of the two methods of treatment is, however, somewhat paradoxical. If the patient qualifies for thiouracil treatment, there is no indication for surgery. If surgery has been chosen because of toxic or other reaction or some contra-indication to thiouracil, it is obviously impossible to use the drug for pre-medication. There are, however, two exceptions. The first is a severe case who has no contra-indication to methyl thiouracil, but for whom operation has been chosen because of inability to attend for regular supervision if treated with thiouracil. The second exception is the patient who, having responded to thiouracil for 18 months to two years, fails to maintain a permanent remission after withdrawal of the drug. It is undesirable for patients to continue taking thiouracil for more than 18 months to two years, since there is some evidence that chronic hypoplasia of the bone marrow may occur and the necessity for regular hospital attendance is conducive to a sense of permanent invalidism.

\section{Does Thiouracil Cure ?}

This question cannot as yet be answered definitely. Strictly speaking the answer is no, since the action is reversible and the thyroxin level of the body rises rapidly after withdrawing the drug. It is probable, however, that in many cases thiouracil does virtually produce a cure by assisting the patient into a natural remission. The long-term results of treatment are now being investigated.

The majority of thyrotoxic patients will respond to treatment by thiouracil or operation, but there remains a small group for whom neither of these forms of treatment is suitable-patients who cannot be treated with thiouracil and who present some contra-indication to operation such as concomitant disease elsewhere or lack of thyroid tissue in the neck after previous operations. There are a number of alternative treatments which may be offered.

\section{X-Ray Therapy}

The effect of irradiating concurrently the thyroid and pituitary gland is by no means so pronounced as that of methyl thiouracil or surgery. But nevertheless irradiation produces a very favourable effect in many cases. It should not, of course, be used if subsequent thyroidectomy is considered, since it fibroses the thyroid gland and may render surgery impossible. The result is usually to induce a remission in the disease which may be permanent, though X-ray therapy should not be relied upon to have much effect in very severe cases.

\section{Lugol's Iodine}

The use of this important drug should be restricted firstly to immediate pre- and postoperative treatment, secondly to thyroid crises and thirdly in cases who have failed to respond to operation, thiouracil or X-ray therapy. Iodine must be given only for short periods, otherwise the patient will acquire a tolerance and may actually become worse. It should be administered for periods of up to three weeks and then discontinued for six to eight weeks. Such tactics will induce remissions or will tide the patient over until a natural one occurs. Often small doses of 5 minims daily of Lugol's iodine are sufficient. Itshould also be remembered that regular administration of Lugol's iodine to non-toxic puberty goitres may be followed by toxicity.

\section{Phenobarbitone}

There is some evidence that this drug, apart from acting as a general sedative, blocks the entrance of thyroxin into the tissue cells. Whether this is true or not, phenobarbitone exerts no marked anti-thyroid action but is useful in highlyexcitable patients during the lag period while thiouracil is exerting its effect after therapy has been first instituted.

In mild cases of primary thyrotoxicosis, the use of phenobarbitone combined with reassurance and rest may maintain the patient in good health until a natural remission occurs, after which he or she may enjoy many years of normal health before a possible exacerbation occurs. There is no indication for rushing into thiouracil therapy in such cases, although they should be seen at frequent intervals so that if the condition deteriorates, this can be instituted without delay.

\section{Drugs still under investigation Ergothionine}

Recently Lawson and Rimington have described the anti-thyroid activity of ergothionine, a methyl betain of 2-thiol-histamine, originally isolated from ergot of rye by Tanret in 1909. This substance is a normal constituent of blood and therefore unlikely to produce any toxic reactions. 
The effect, when administered to rats by subcutaneous injection, was found to be comparable to that of thiouracil, which belongs to the same chemical type.

So far no reports of work on human thyrotoxicosis have been published and there are difficulties in obtaining sufficient ergot for the manufacture of ergothionine in order to conduct clinical trials, but the drug appears promising.

Vitamins of the $B_{2}$ complex

A pseudo-antagonistic action between thyroxin on the one hand and pantothenic acid and paraaminobenzoic acid (vitamin $\mathrm{H}$ ) on the other, has been postulated. Mackenzie and Mackenzie, in very early experiments with thiouracils, found that their goitrogenic action in rats was slightly enhanced by the concurrent administration of paraaminobenzoic acid. Berman in America has reported six cases of thyrotoxicosis successfully treated with this compound. Recently, however, Williams of Boston, in a series of eight cases, has shown that para-aminobenzoic acid exerts no marked antithyroid action. On the other hand, the use of 3-5-diiodopara-aminobenzoic acid produced a rapid response in a few patients. Abelin has shown in rats that pantothenic acid will prevent the effects of thyroglobulin administered concurrently. No clinical trials have been carried out owing to the difficulty of obtaining sufficient quantities of this latter vitamin for treatment.

Para-aminobenzoic acid, however, is cheap and easy to obtain and according to reports on its use in typhus during the late war (Yeomans, et al., I944), virtually non-toxic, although leucopenia may occur with doses greater than 2 gms. twohourly. During the last six months I have treated six cases with sodium para-aminobenzoate by oral administration, using 3 gms. daily. No toxic reactions have occurred, and the mixture is not unpleasant to take. The results are not as yet conclusive, but it would seem that P.A.B. exerts a slight anti-thyroid effect and is free from toxicity. The investigation is continuing.

ABELIN, I. (1945), Experientia; 1, 231 .

ALBUTT, C. (1897), System of Medicine, IV, 502.

ANSBACHER, S. (1944), Vitamins and Hormones, 2, 215.

ASTWOOD, E. B. (1943) Y.A.M.A., 122, 78 .

ASTWOOD, E. B., SULLIVAN, J., BISSELL, A., and TYSLOWITZ, R. (1943), Endocrinology, 37, 2, 2 10.

ASTWOOD, E. B., and VAN'DER LAAN, W.' P.'(1945), f. Clin. Endocrinol., 5, 424.

BARTELS, E. 'C.' (1945), Arch. Intern. Med., 22, 365.

BENDER, R., and POIROT, G. (1946), Bull. et Mem de la Soc. $M e d$. des Hop. de Paris, Nos. 3-7, 127.

BERMAN, L. (1945), Proc. Soc. Exp. Biol. and Med., $59,1,70$.

DUNLOP, D. M., and DONALD, J. B. (1945), Br. Med. Fourn.,

FRIESLEBEN, E., and KJERULF-JENSEN, K. (1946), Acta Pharm. et Toxicol., 2, 307.

GARGIL and LESSES (1945), 7.A.M.A., $127,14,890$.

GIBSON, P. C., and QUINLAN, J. J. (1945), Lancet, 2, 108.

HIMSWÓRT'T,' H. P. (1943), Lancet, 2, 465 .

HIMSWORTH, H. P. (1944)', Proc. Roy. Soc. Med., 37, 693.

HIMSWORTH, H. P., MORGANS, M. E., and TROTTTER, W. R., Lancet, $\mathbf{x}, 241$

HERTZ, S., and ROBERTS, A. (1946), Y.A.M.A., 131, 7, 422.

KAHN, and STOCK (1944), f.A.M.A., 126, 6, 358.

\section{Radio-active iodine}

This substance is not yet available in this country, but reports from the United States suggest that it may replace methyl thiouracil in the future (Williams, I947 ; Hertz and Roberts, 1946). Radio-active iodine when given by mouth is rapidly taken up by the thyroid gland, where it remains for several months. One dose may be sufficient to produce a lasting remission in the disease. The disadvantage lies in the uncertainty of the effect of a given dose, so that myxoedema may inadvertently be produced. Hypothyroidism, of course, can still be controlled by the administration of thyroid extract. A latent period of up to two months after administration occurs before radio-iodine takes effect.

Thyrotoxicosis still remains a disease the cause of which we are ignorant, but the sufferer today can look forward to a very much brighter future than his or her predecessor of 15 or 20 years ago. Thiouracil will relieve the majority of patients and is indicated in all cases except those with large goitres, tracheal compression, malignancy, a history of agranulocytosis, or inability to attend for regular supervision. For these cases modern surgery offers a satisfactory method of treatment.

It is doubtful if it is desirable for patients to continue taking thiouracil compounds for longer than two years, since there may be danger of producing irreversible bone marrow changes. Also the constant supervision necessary is a psychological and economic drawback to the patient. Patients who, after treatment for more than two years, fail to sustain a remission when the drug is withdrawn, should be considered as possible candidates for surgery.

Radio-active iodine offers a cheering prospect, and may replace thiouracil completely.

Acknowledgement. Much of the original work from which conclusions are drawn was carried out in collaboration with Dr. Andrew Wilson.

\section{BIBLIOGRAPHY}

KORNBERG, et al. (1944), f. Bio. Chem., 155, 193.

KJERULF-JENSEN, K., and MEULENGRACHT, E. (1946), Nordisk Medecin, $32,2809$.

LAHEY, F. H., BAR'TELS, et al. (1947), Surg. Gynaec. and Obstetrics, 81, 425.

LAHEY, F. H. (1947), Cited by Lancet Editorial, 2, 512.

LAWSON, A., and RIMINGTON, C. (1947), Lancet, I, 586.

LEYS, D. (1945), Lancet, $1,46 \mathrm{r}$.

LIMARZI, L. R., et al. (1946), f. Lab. and Clin. Med., 31, 4, 470 LINNELL, J., KEYNES, G., and PIERCY, J. (1946), Br. Med. Fourn., 2,449 .

LIVINGSTÓNE and LIVINGSTONE (1947),Y.A.M.A., 135, 7, 422

MACKENZIE, C. G., and J. B. (1943), Endocrinol., 37, 2, 185.

McCULLAGH, E. P.'(1946), Cleveland. Clin. Quart., 13, 2.

MCCULLAGH, E. P., et al.'(1946), Ibid, 13, 232.

MORGANS, M. E. (1947), Lancet, 1 , 519.

MOSCHOWITZ, E. (1946), Arch. Intern. Med. 78, 497.

NEWCOMBE, P. B., and DEANE, E. W. (1944), 1, 179.

PAPP, C. (1045), Post Grad. Med. fourn., 21, 45.

SLOAM and SHORR (1944), Science, $99,2572,305$.

WILLIAMS, R. H. (1947), Arch. Int. Med., 80, I, 1 I.

WILSON, A. (1946), Lancet. $1,64^{\circ}$.

WILSON' A., and GOODWIN, J. (1947), Lancet, r, 669.

YEOMANS, et al. (1944), F.A.M.A., 126. 349. 